\title{
Restrict genetic susceptibility tests
}

Sir - Given the extent of current research into both genetics and mental disorders, the Nuffield Council on Bioethics has undertaken an inquiry into issues raised when these fields come together. The report, 'Mental disorders and genetics: the ethical context', ${ }^{1}$, published on 23 September, is primarily concerned with whole persons and not simply with their genes. This broad and humanistic perspective may be contrasted with a reductionist approach which risks undermining both moral responsibility and social solidarity. Genetic information about mental disorders may alter the way those affected are viewed by others and in particular, the stigma they suffer.

The discovery of mutations associated with the 'traditional' Mendelian single gene disorders has had profound implications for clinical diagnosis and predictive testing. However, the Nuffield inquiry concluded that genetic tests for the diagnosis of the common mental disorders with more complex causes will not be particularly useful in the near future. Even if a number of susceptibility genes were identified for a particular disorder, the Nuffield Council takes the view that, without an understanding of their interaction, they would not be adequate for predicting individual risk in a clinical setting. It has therefore recommended that genetic testing for susceptibility genes which offer relatively low predictive or diagnostic certainty be discouraged unless and until there is clear medical benefit to the patient.

The Nuffield Council would construe as unethical the exclusion of people with a mental disorder from genetic research, as the identification of associated genes may lead to more effective drug treatments. The view is taken therefore that non-therapeutic research should be considered ethically acceptable even when it involves people lacking the capacity to consent to participation, subject to strict safeguards. While the best safeguard against new eugenic pressures is freely given, properly informed consent, guidelines for the establishment and maintenance of genetic registers are needed.

Sandy Thomas, (Director), Fiona Caldicott ${ }^{*}$, (Chairman of the Nuffield Council on Bioethics Working Party on Mental Disorders and Genetics), Chris Barchard*, Rachel Bartlett, John Haldane ${ }^{\star}$, Sonia Hornby $^{\star}$, Peter McGuffin ${ }^{\star}$,Nigel Pleming ${ }^{\star}$, Martin Richards ${ }^{\star}$, Pamela Taylor ${ }^{\star}$, Andrew Wilkie $^{\star} \&$ Sally Young ${ }^{\star}$

Nuffield Council on Bioethics,

28 Bedford Square,

London WC1B 3EG, UK

${ }^{*}$ Member of the Working Party

1. Mental disorders and genetics: the ethical context (Nuffield Council on Bioethics, London, 1998).

\section{Star chambers will result in injustice}

Sir - Jon Turney's generally favourable review of my book The Baltimore Case offers the judgement that the affair was "not of enormous significance, except for the victims" (Nature 395, 30-31; 1998). That is to miss the point of historical importance of the case, and a major point of the book. The case had great significance for the civil rights of scientists charged with fraud.

Thereza Imanishi-Kari was investigated relentlessly by a congressional subcommittee and by an entity in the US Department of Health and Human Services now named the Office of Research Integrity (ORI). In both venues, she was denied elementary protections of due process, especially the right to see and evaluate evidence and the right to confront and cross-examine witnesses against her. So she could not defend herself effectively. The miscarriage of justice was put right because Imanishi-Kari's tenacious refusal to concede ultimately gained her access to an appeals board that afforded her full due-process rights.

I think it perfectly legitimate - indeed, obligatory - for government authorities to call to account publicly supported scientists who cheat. My quarrel with the investigation of Imanishi-Kari is not primarily, as Turney says, that the authorities went after "the wrong people". It is that the ORI went after Imanishi-Kari in the manner of a Star Chamber. The denial of due-process rights to anyone, innocent or guilty, is indefensible. The ORI investigators defended their procedures on the grounds that they were not conducting a legal inquiry but engaging in a dialogue between scientists. But, if a criminal penalty was not necessarily at stake, careers and reputations were.

The case has already had a major impact on how such charges in biomedical research are handled in the United States - by, for example, establishing the right of all accused scientists to use the appeals process. The case is deeply instructive for scientists and policymakers in the United States, where the procedures for handling fraud cases are still evolving, and in other countries, where questions of how charges of scientific fraud should be adjudicated are commanding increasing attention. The ORI's original procedures threatened the civil rights of every scientist who might be charged with fraud.

Daniel J. Kevles

California Institute of Technology (228-77),

Pasadena, California 91125, USA

e-mail:kevles_d@caltech.edu

Was Moses the first ecologist?

Sir - A recent UK television programme, Equinox: The Ten Plagues of Egypt (Channel 4 ), gave a modern reappraisal of the sequence of biological and meteorological catastrophes recorded in the biblical book of "Exodus".
It was proposed that, within the unavoidable constraints of the language used, the account can be taken as factual and in particular that the sequence of these events is significant. The trigger was a red algal bloom that killed much of the life in the Nile, especially the fish which normally kept the toad population under control. It was argued that this led, by plausible steps, to plagues of flies and midges and hence to animal and human plagues for which they were vectors. The final catastrophe arose from the storage of wet grain contaminated by locust droppings which led to the poisoning of human and animal food supplies with microtoxins.

The corollary, which the programme did not stress, is the predictability of much of this sequence. Algal blooms must have occurred before (although perhaps not on such an epic scale) and farmers must have been forced to store wet grain in earlier harvests because of bad weather conditions. Observers must have seen and recorded the results. The educated elite must have known what to expect (and Moses had been adopted by Pharaoh's daughter and educated as a prince in the royal court). Armed with this knowledge, he would have been able to predict publicly, to good effect, the exact form each of the biological catastrophes would take, before it occurred.

The mistake was to educate Moses. One can picture the Pharaoh concurring with Oscar Wilde that no good deed goes unpunished.

John Lydon

School of Biochemistry and Molecular Biology, University of Leeds, Leeds LS2 9JT, UK 